Situs Jurnal : $\underline{\text { http://ejurnal.stiepancasetia.ac.id/index.php/jieb }}$

Jilid 4 Nomor 1 Maret 2018

Hal $077-086$

\title{
STRATEGI PEMASARAN PADA LEMBAGA BIMBINGAN BELAJAR GO SMART BANJARBARU
}

\section{Muhammad Rizal dan Siti Paujiah*}

Abstract: This research is to know Go Smart marketing strategy and find the right marketing strategy in mega marketing which includes 7P (product, price, promotion, place, people, Proces, Physical Evidence) at the Institute of Tutoring Go Smart Banjarbru to reach the target. The method used is qualitative descriptive to answer the problems that have been found by researchers and conducted analysis of phenomena - phenomena that occur in Go Smart accompanied by SWOT analysis to review the strengths and opportunities owned by the institution and then utilized as much as possible to reduce the weaknesses and threats that faced. After the SWOT analysis and the formulation of new strategies, it turns out that Go Smart still gets strtagei marketing constraints from various sectors. For the future, Go Smart Banjarbaru needs to maintain a well-executed strategy and develop a more varied product differentiation and prioritize promotional activities to various schools at certain moments.

\section{Keywords: Institute of Tutoring, Marketing Mix, SWOT Analysis, Number of Students}

Abstrak: Penelitian ini adalah untuk mengetahui strategi pemasaran Go Smart dan menemukan strategi pemasaran yang tepat dalam mega marketing yang meliputi 7P (product, price, promotion, place, people, Proces, Physical Evidence) pada Lembaga Bimbingan Belajar Go Smart Banjarbaru untuk mencapai target. Metode yang digunakan adalah kualitatif deskriptif dapat menjawab permasalahn yang telah ditemukan oleh peneliti dan dilakukan analisa terhadap fenomena - fenomena yang terjadi di Go Smart disertai dengan analisi SWOT untuk meninjau kekuatan dan peluang yang dimiliki lembaga dan kemudian dimanfaatkan semaksimal munkin untuk mengurangi kelemahan dan ancaman yang dihadapi. Setelah di lakukan analisa SWOT dan perumusan strategi baru, ternyata Go Smart masih mendapat kendala strtagei pemasaran dari berbagai sektor. Untuk kedepannya, Go Smart Banjarbaru perlu mempertahankan strategi yang telah berhasil dijalankan dan mengembangkan diferensiasi produk yang lebih bervariatif serta memprioritaskan kegiatan promosi ke baerbagai sekolah pada momen-momen tertentu.

Kata kunci : lembaga bimbingan belajar, marketing mix, analisis SWOT, jumlah siswa

\section{Latar Belakang}

Menurut UUD 1945 pasal 31 dan UU No. 2 tahun 1989 tentang system pendidikan nasional disebutkan bahwa penyelenggaraan pendidikan menjadi tanggungjawab antara pemerintah dan masyarakat. Hal tersebut menunjukkan bahwa penyelenggaraan pendidikan tidak hanya di sekolah formal saja tetapi juga dapat diselenggarakan oleh lembaga luar sekolah semacam Bimbingan Belajar. Oleh karena itu, lembaga bimbingan belajar mempunyai dasar yang kuat sebagai wujud partisipasi masyarakat dalam mewujudkan cita - cita pendidikan mencerdaskan kehidupan bangsa. 
Pada perkembangannya, sekolah menjadi hal yang penting, bahkan utama bagi sebagian besar anak - anak dan remaja di dunia, tak terkecuali di Indonesia. Saat ini, anak Indonesia yang bersekolah tidak hanya untuk sekedar sekolah saja. Namun terdapat standar tinggi yang harus diraih di sekolah yang akrab dengan istilah standar ketuntasan minimum baik baik untuk ujian tengah semester, ujian akhir semester, ujian kenaikan kelas, bahkan untuk Ujian Nasional. Kriteria ketentuan untuk kompetensi dasar pada masing - masing mata pelajaran yang di tentukan sendiri oleh sekolah umumnya $75 \%$. Tentutan yang makin berat tersebut, memberikan ide bagi sebagian orang untuk membuat usaha yang kelak disebut Lembaga Bimbingan Belajar.

Dalam rangka pemenuhan kebutuhan akan kemampuan pengembangan potensi dalam proses pembelajaran banyak bermunculan lembaga-lembaga pendidikan yang menyediakan jasa kursus. Salah satu industri jasa yang berkembang saat ini adalah jasa bimbingan belajar. Pada saat ini banyak Lembaga Bimbingan Belajar yang saling bersaing dengan menawarkan berbagai jenis program dan metode pembelajaran yang menarik. Banyak siswa yang dengan antusias mengikuti bimbingan belajar karena belajar di Lembaga Bimbingan Belajar tidak sekedar berupa materi pelajaran semata, tetapi juga disampaikan tentang kiat - kiat belajar efektif, kiat - kiat belajar di perguruan tinggi dan informasi seputar perguruan tinggi. Kebanyakan tujuan siswa mengikuti bimbingan belajar adalah untuk memasuki perguruan tinggi negeri. Terdapat pula alasan lain yang mengatakan bahwa kemampuan guru di sekolah terbatas, kurangnya fasilitas belajar yang memadai, serta tuntutan kurikulum yang tidak realitas menyebabkan siswa mencari alternatif lain untuk belajar di luar sekolah. Sekolah juga dianggap tidak mampu menyediakan semua kebutuhan yang diperlukan siswa terlebih lagi untuk berebut kursi di PTN yang diidam-idamkan.

Go Smart Sebagai sebuah lembaga pendidikan nonformal ataupun lembaga bimbingan belajar yang menyediakan jasa pendidikan tentunya memiliki tujuan untuk dapat hidup dan berkembang, tujuan ini hanya akan dapat dicapai apabila bagian pemasaran melakukan strategi yang mantap untuk dapat menggunakn kesempatan atau peluang yang ada dalam pemasran, sehingga posisi atau kedudukannya dapat dipertahankan dan sekaligus ditingkatkan

Strategi-strategi pemasaran merupakan sarana mencapai sasaran pemasaran dan umumnya berhubungan dengan 4P, anatara lain: produk (product), harga (price), tempat (place), dan promosi (promotion). Strategi - strategi pemasran yang umum sekarang dikembangkan menjadi sub sasaran khusus, yang masing - masing didukung oleh strategi dan pernyataan tindakan yang akan dilakukan secara lebih terperinci. Banyak organisasi menggunakan berbagai strategi untuk meningkatkan pangsa pasar, salah satunya melalui strategi kualitas. Dalam strategi pemasaran, konsumen merupakan tujuan jangka panjang perusahaan. Tujuan pemasaran adalah untuk memenuhi dan memuaskan kebutuhan serta keinginan konsumen.

Adapun pesaing-pesaing Bimbingan Belajar yang ada di Banjarbaru yaitu : Ganesa Operasional, Primagama dan Prima Mandiri. Maka dari itu Go Smart harus lebih teliti dalam penerapan strategi pemasaran. Akan tetapi, dalam pemasaran jasa ada elemen - elemen strategi pemasaran 4P yaitu: produk (product), harga (price), promosi (promotion) serta tempat (place) dikontrol dan dikoordinasikan untuk keperluan komunikasi dan memuaskan jasa. Elemen elemen tersebut adalah orang (people), lingkungan fisik atau bukti fisik (physical evidence), dan prosos jasa itu sendiri (proces) dengan demikian 4P yang pada mulanya menjadi bauran pemasaran perlu menjadi 7P jika ingin digunakan dalam pemasaran jasa.

Dengan melihat kondisi yang ditampilkan pada tabel 1 dan 2 terlihat bahwa terjadi penurunan jumlah siswa yang ikut bimbingan belajar di Lembaga Bimbingan Belajar Go Smart Banjarbaru setiap tahunnya, maka di perlukan suatu strategi pemasaran yang lebih baik. 
Tabel 1. Program Bimbingan Selama 1 Tahun Belajar Go Smart Banjarbaru

\begin{tabular}{cccc}
\hline No. & Kelas & Jumlah Siswa Per Kelas & \multicolumn{2}{c}{ Harga } \\
\hline 1. & Reguler & 20 & $\mathrm{Rp} 3.500 .000$ \\
\hline 2. & Silver & 10 & $\mathrm{Rp} 6.000 .000$ \\
\hline 3. & Gold & 8 & $\mathrm{Rp} 9.000 .000$ \\
\hline 4. & Super Gold & 4 & $\mathrm{Rp} 12.000 .000$ \\
\hline
\end{tabular}

Tabel 2. Jumlah Pencapaian Siswa Selama 3 Tahun Terakhir

\begin{tabular}{cccc}
\hline No. & Tahun Ajaran & Jumlah & Target \\
\hline 1. & $2014-2015$ & 612 & 750 \\
\hline 2. & $2015-2016$ & 521 & 750 \\
\hline 3. & $2016-2017$ & 482 & 750 \\
\hline
\end{tabular}
berikut:

Berdasarkan uraian latar belakang di atas dapat diidentifikasikan permasalahan sebagai

1. Bagaimana penerapan strategi marketing 7P yang dilakukan Lembaga Bimbingan Belajar Go Smart Banjarbaru untuk meningkatkan jumlah siswa?

2. Bagaiamana penerapan strategi marketing $7 \mathrm{P}$ yang harus dilakukan untuk meningkatkan jumlah siswa pada Lembaga Bimbingan Belajar Belajar Go Smart Banjarbaru dengan menggunakan analisis SWOT?

\section{Kajian Literatur}

Menurut Kotler dan ketler (2012:48) manajemen pemasaran adalah kegiatan pengaturan secara maksimal fungsi - fungsi pemasaran agar kegiatan pertukaran atau menyampaikan barang atau jasa dari produsen ke konsumen dapat berjalan lancar dan memuaskan.

Menurut Alma (2013:130) manajemen pemasaran adalah kegiatan menganalisa, merencanakan, mengimplementasikan dan mengawasi segala kegiatan guna memperoleh tingkat pertukaran yang menguntungkan dengan pembeli sasaran dalam rangka mencapai tujuan perusahaan. Menurut Abdullah dan Tantri (2015:22) manajemen pemasran adalah proses yang mencakup analisis, perencanaan, pelaksanaan dan pengawasan juga mencakup barang, jasa serta gagasan berdasarkan pertukaran dan tujuannya adalah memberikan kepuasan bagi pihak yang terlimbat.

Menurut Tjiptono (2014:5) perkembangan dalam konsep pemasaran meliputi lima tingkatan, yaitu :

1. Konsep Produksi

2. Konsep Produk

3. Konsep Penjualan

4. Konsep Pemasaran

5. Konsep Pemasaran Sosial

Menurut Assauri (2104:168) strategi pemasaran pada dasarnya adalah rencana yang menyeluruh, terpadu dan menyatu dibidang pemasaran, yang memberikan panduan tentang kegiatan yang akan dijalankan untuk dapat tercapainya tujuan pemasaran suatu perusahaan. Dengan kata lain, strategi pemasaran adalah serangkaian tujuan dan sasaran, kebijakan dan aturan yang memberi arah kepada usaha - usaha pemasaran perusahaan dari waktu ke waktu, pada masing - masing tingkatan dan acuan serta alokasinya, terutama sebagai tanggapan perusahaan dalam menghadapi lingkungan dan keadaan persaingan yang selalu berubah. 
Konsep bauran pemasaran tradisional menurut Hurriyat 4P, yaitu produk (product), harga (price), tempat/lokasi (place), promosi (promotion). Sementara itu, untuk pemasaran jasa perlu bauran pemasaran yang diperluas, dengan menambah unsur non tradisional marketing mix, yaitu orang (people), fasilitas fisik (physycalevidence), dan proses (process), Publik Relation sehingga menjadi 8P yang serinng dikenal dengan Mega Marketing. Masing - masing Mega Marketing yang terdiri dari tujuh unsur bauran pemasaran tersebut saling berhubungan dan tergantung satu sama lainnya dan mempunyai suatu bauran yang optimal sesuai dengan karakteristik segmennya. Oleh Zeithami dan Beitner Mega Marketing terdiri dari 8P yaitu product, price, place, promotion, people, physical evidence dan process.

Teknik analisis SWOT yang digunakan adalah sebagai berikut :

1. Analisis Internal

a. Analisis Kekuatan (Strenght)

Setiap perusahaan perlu menilai kekuatan dan kelemahannya dibandingkan para pesaingnya. Penilaian tersebut dapat didasarkan pada faktor-faktor seperti teknologi, sumber daya finansial, kemampuan kemanufakturan, kekuatan pemasaran, dan basis pelaggan yang dimiliki. Strenght (kekuatan) adalah keahlian dan kelebihan yang dimiliki oleh perusahaan pesaing.

\section{b. Analisis Kelemahan (Weaknesses)}

Merupakan keadaan perusahaan dalam menghadapi pesaing mempunyai keterbatasan dan kekurangan serta kemampuan menguasai pasar, sumber daya serta keahlian. Jika orang berbicara tentang kelemahan yang terdapat dalam tubuh suatu satuan bisnis, yang dimaksud ialah keterbatasan atau kekurangan dalam hal sumber, keterampilan dan kemampuan yang menjadi penghalang serius bagi penampilan kinerja organisasi yang memuaskan. Dalam praktek, berbagai keterbatasan dan kekurangan kemampuan tersebut bisa terlihat pada sarana dan prasarana yang dimiliki atau tidak dimiliki, kemampuan manajerial yang rendah, keterampilan pemasaran yang tidak sesuai dengan tuntutan pasar, produk yang tidak atau kurang diminta oleh para pengguna atau calon pengguna dan tingkat perolehan keuntungan yang kurang memadai.

c. Opportunities (peluang)

Opportunities (peluang) merupakan kondisi peluang berkembang di masa datang yang terjadi. Kondisi yang terjadi merupakan peluang dari luar organisasi, proyek atau konsep bisnis itu sendiri. misalnya kompetitor, kebijakan pemerintah, kondisi lingkungan sekitar.

\section{Analisis Eksternal}

a. Analisis Peluang (Opportunity)

Setiap perusahaan memiliki sumber daya yang membedakan dirinya dari perusahaan lain. Peluang dan terobosan atau keunggulan bersaing tertentu dan beberapa peluang membutuhkan sejumlah besar modal untuk dapat dimanfaatkan. Dipihak lain, perusahaan-perusahaan baru bemunculan. Peluang pemasaran adalah suatu daerah kebutuhan pembeli di mana perusahaan dapat beroperasi secara menguntungkan.

b. Analisis Ancaman (Threats)

Ancaman adalah tantangan yang diperlihatkan atau diragukan oleh suatu kecenderungan atau suatu perkembangan yang tidak menguntung-kan dalam lingkungan yang akan menyebabkan kemerosotan kedudukan perusahaan. Pengertian ancaman merupakan kebalikan pengertian peluang. Dengan demikian dapat dikatakan bahwa ancaman adalah faktor-faktor lingkungan yang tidak menguntungkan suatu satuan bisnis. 


\section{Metode Penelitian}

Penelitian ini menggunakan metode kualitatif deskriptif, yaitu suatu teknik dengan cara mengumpulkan data, mengelompokkan, menganalisis, dan kemudian menginterprestasikan sehingga memberikan gambaran alternatif masalah yang dihadapi. Pendekatan yang digunakan dari peneliti ini adalah mega marketing (Produk, tempat, promosi, orang, proses, harga, dan bukti fisik). Jenis data yang digunakan dalam penelitian ini adalah:

1. Data kualitatif yaitu meneliti dengan berfikir secara induktif, menangkap berbagai fakta atau fenomena-fenomena sosial melalui pengamatan dilapangan, kemudian menganalisisnya dan berupaya melakukan teorisasi berdasarkan hal yang diamati.

2. Data kuantitatif adalah data berupa angka-angka yang dihitung serta mempunyai satuan tertentu dan dapat diapresiasikan secara matematis, berupa angka-angka.

Data dikumpulkan dengan menggunakan Library Reseach (penelitian kepustakaan) yang dilakukan dengan mengumpulkan sejumlah data dengan jalan mmembaca dan menelusuri literatur-literatur baik berupa buku-buku, majalah, dan tulisan-tulisan ilmiah yang berhubungan dengan masalah yang akan dibahas. Field Reseach (Penelitian lapangan) yaitu penelitian kualitatif mengamati dan berpartisifasi secara langsung yaitu sebagai berikut: Observasi, Wawancara, Dokumentasi.

Untuk mengidentifikasi teori - teori yang digunakan dalam penelitian ini, maka definisi operasional variabel yang dikemukakan adalah:

1. Manajemen pemasaran adalah kegiatan pengaturan secara maksimal fungsi - fungsi pemasaran agar kegiatan pertukaran atau menyampaikan barang atau jasa dari produsen ke konsumen dapat berjalan lancar dan memuaskan.

2. Konsep pemasaran adalah falsafah atau anggapan yang diyakini perusahaan sebagai dasar dari setiap kegiatannya dalam memuaskan kebutuhan dan keinginan konsumen.

3. Strategi pemasaran adalah suatu pola fundamental, dimana terdapat perencanaan pemasaran, pengarahan sumber daya, serta interaksi dengan pasar, pesaing, konsumen, dan sebagainya.

4. Mega marketing merupakan kombinasi dari beberapa variabel yang merupakan inti dari pemasaran yaitu product, price, promotion, place, people, process, physical evidence.

Teknik Analisis data yang digunakan dalam penelitian ini meliputi:

1. Reduksi Data

Dalam penelitian ini peneliti akan memilih data yang berkaitan dengan masalah dan merangkum data penting yang ditemukan dilapangan sesuai dengan kajian teoritik pokok untuk mempermudah peneliti menentukan strategi yang tepat dalam pengumpulan data selanjutnya.

2. Data yang telah direduksi dari hasil pengumpulan data melalui wawancara dan untuk mendapatkan hasil strategi yang baik, peneliti menggunakan analisis SWOT (Streenght, Weakness, Opportunity, Threath). melalui tiga tahap analisis yaitu:
a. Tahap pengumpulan data(eksternal dan internal)
b. Tahap analisis (Matriks SWOT, Matriks imternal eksternal)
c. Tahap pengambilan keputusan.

\section{Hasil Penelitian dan Pembahasan}

Banyak strategi pemasaran yang dapat dilakukan pihak lembaga sebagaimana yang telah dipaparkan pada kajian teoritik. Salah satunya adalah penerapan mega marketing $7 \mathrm{P}$ (product, price, place, promotion, people, physical evidence, process). 
Strategi pemasaran Go Smart Banjarbaru yang akan dideskripsikan, dianalisis dan diinterpretasikan satu-persatu dan disusun perumusan strategi baru sebagai berikut:

1. Product (Produk)

Go Smart Banjarbaru memiliki program pendidikan yang disesuaikan dengan kebutuhan siswa. Sebelum menyediakan program di Go Smart, terlebih dahulu pihak Go Smart melakukan survey ke wilayah sekitar Banjarbaru untuk mengetahui seberapa besar kebutuhan siswa akan bimbingan belajar.

2. Price (Harga)

Dalam penentuan harga Go Smart Banjarbaru bisa dibilang tidak terlalu mahal bahkan bisa dibilang lebih murah dari bembel lainnya.

3. Promotion (Promosi)

Promosi merupakan bagian terpenting dalam pemasaran, beragam cara dalam memasarkan produk telah dilakukan dan Go Smart melakukan promosi dengan cara sebagai berikut:

a. Menggelar acara tes uji coba UAS, UAN setingkat SD,SMP dan SMA

b. Sebar brosur pada saat golden moment (kenaikan kelas, penerimaan rapot kelas)

c. Melakukan acara sosialisasi marketing ke kelas yang telah di setujui oleh pihak sekolah (kepala sekolah).

d. Menggunakan siswa Go Smart Banjarbaru sebagai pemasaran dengan jalan titip voucher untuk teman - temannya.

\section{Place (Tempat)}

Go Smart Banjarbaru bertempat di Ruko jalan panglima batur timur No. 19G dan F Banjarbaru, tempat tersebut strategis karena terletak di daerah dekat pemerintahan kota Banjarbaru dan banyak sekolah seperti: SMA 2, SMK TELKOM, SMP 2, SMP dan SMA Qardhan, SD KOMET, dll.

\section{People (Orang)}

Para tenaga kerja yang ada di Go Smart Banjarbaru meliputi: Tentor, Staf keuangan akademik dan PSDM, kepala Cabang, Petugas Administrasi Cabang, OB dan sebagainya.

a. proses pemilihan tentor yang dilakukan oleh Go Smart Banjarbaru adalah sebagai berikut:

1) Tes tertulis.

2) Micro teaching yaitu penilaian mengajar di kelas oleh tentor senior.

3) Wawancara.

4) Observasi kelas yaitu melihat tentor senior mengajar di kelas.

5) Di coba di beri jam mengajar.

6) Jika nilainya bagus diterima menjadi tentor tetap

b. Staf - Staf Go Smart pula mendapatkan pelatihan tersendiri sesuai dengan bidangnya dan diajarkan pula bagaimana melayani konsumen sedangkan untuk petugas administrasi cabang selain dituntut untuk ramah dan bersahabat dengan siswa, tentor - tentor maupun calon siswa juga harus mempunyai keahlian lainnya seperti mengoperasikan komputer dan hal pembukuan.

6. Process (proses)

Proses adalah kegiatan yang menunjukkan bagaimana pelayanan diberikan kepada calon siswa maupun siswi di Lembaga Bimbingan Belajar Go Smart Banjarbaru. 
Proses pelayanan yang diberikan kepada calon siswa di Lembaga Bimbingan Belajar Go Smart Banjarbaru, yang ingin mengetahui produk / jasa melalui telpon maupun datang langsung ke tempat Lembaga Bimbingan Belajar Go Smart adalah:

a. Sambut calon siswa / wali / orang tua siswa di Lemabaga Bimbingan Belajar Go Smart Banjarbaru dalam keadaan berdiri, senyum serta salam dan mempersilahkan duduk.

b. Menanyakan jenis program yang ingin di peroleh atau dijalankan oleh calon siswa / wali / orang tua siswa di Lembaga Bimbingan Belajar Go Smart Banjarbaru.

c. Menanyakan layanan yang ingin digunakan serta menjelaskan keunggulannya.

7. Physical Evidence (bukti fisik)

Physical Evidence merupakan hal nyata yang turut mempengaruhi keputusan siswa maupun calon siswa / wali / orang tua siswa di Lemabaga Bimbingan Belajar Go Smart Banjarbaru untuk menggunakan dan memakai produk atau jasa yang ditwarkan oleh lembaga pendidikan ini.

Setelah dilakukan penelitian data menggunkan analisi SWOT terhadap yang menjadi fokus penelitian, maka dibuatlah matriks SWOT dan perumusan strategi pemasaran Go Smart Banjarbaru untuk membenahi kelemahan dan ancaman yang dimiliki oleh Go Smart Banjarbaru dengan menyesuaikan kekuatan dan peluang yang dimiliki oleh Go Smart Banjarbaru. Perumusan strategi tersebut dapat dilihat pada tabel berikut ini.

Berdasarkan analisis tersebut menunjukan bahwa kinerja lembaga dapat ditentukan oleh kombinasi faktor internal dan eksternal. Kombinasi kedua faktor tersebut ditunjukkan dalam diagram hasil analisis SWOT sebagi berikut:

\section{Stategi SO (Mendukung Strategi Grwoth)}

Yaitu dengan memanfaatkan seluruh kekuatan dan memanfaatkan peluang sebesar besarnya. Memanfaatkan seluruh kekuatan dan kualitas Lembaga Bimbingan Belajar Go Smart Banjarbru dengan meningkatkan kulitas produk, meningkatkan pelayanan, melakukan kerjasama ke sekolah untuk mengadakan bimbingan sesuai jadwal sekolah, melakukan kerjasama Try out untuk siswa kelas akhir, makin gencak melakukan promosi, membuat jam belajar yang sesuai dengan kebutuhan siswa, dan memanfaatkan berbagai media sosial alat untuk promosi.

\section{Strategi ST (Mendukung Strategi Diversifikasi)}

Strategi dengan memanfaatkan seluruh kekuatan yang dimiliki lembaga untuk menagatsi ancaman yaitu melalukan kerjasama dengan sekolah saat pengambilan rapot, melakukan sosialiasai ke siswa kelas ujung seperti 6 SD, 9 SMP, 12 SMA untuk memperkenalkan trik cara cepat menjawab soal Ujian Nasional, melakukan inovasi berkala untuk menjaga kualitas produknya dan mempertahankan citra Go Smart sebagai Lembaga Pendidikan yang baik dalam prestasi melalui pengkatan kualitas produknya.

3. Strategi WO (Mendukung Strategi Tunrn-Around)

Strategi ini diterapkan berdasarkan pemanfaat peluang yang ada dengan cara meminimalkan kelemahan yang ada yaitu mengembangkan kemampuan karyawan dalam mengikuti pelatihan dari Go Smart, mengembangkan penyediaan tentor di Go Smart Banjarbaru sebagai pengganti tentor yang berhalangan serta melakukan perekrutan karyawan baru untuk dijadikan sebagai Staf Marketing. 


\section{Strategi WT (Mendukung Strategi Defensif)}

Strategi ini didasarkan pada kegiatan yang bersifat defensive dan berusaha meminimalkan kelemahan yang ada serta menghindari ancaman yaitu:

a. Mengadakan evaluasi mengenai produk yang dihasilkan secara berkala, Menyediakan tentor yang unggul dan melakukan pelatihan bagi tentor agar mengeuasai dan memiliki trik-trik dalam mengajar trutama pelajaran Matematika dan Fisika.

b. Menambah potongan diskon kepada siswa peringkat 6 sampai dengan 10 .

Strategi pemasaran merupakan seperangkat taktik untuk pemasaran yang dapat dikontrol meliputi produk, harga, tempat, promosi, orang (sumber daya manusia), proses, dan bukti fisik. 7P yang dipadukan perusahaan untuk meningkatkan jumlah siswa oleh pihak Lembaga Bimbingan Belajar Go Smart Banjarbaru. Unsur - unsur strategi pemasaran ini saling terkait, dibaurkan, diorganisir dan digunakan dengan tepat sehingga Lembaga Bimbingan Belajar Go Smart Banjarbaru dapat mencapai tujuan dengan efektif sekaligus memuaskan kebutuhan dan keinginan siswanya. Menyikapi atas strategi pemasaran yang dilakukan oleh pihak Lembaga Bimbingan Belajar GO Smart Banjarbaru, maka pengelolaan atas strategi pemasaran yang sebaiknya dilakukan oleh pihak perusahaan jasa adalah dengan beberapa tindakan perbaikan yang perlu dikaji yang nantinya dapat meningkatkan jumlah siswa seprti perbaikan strategi pemasaran 7P seharunya serta di analis dengan SWOT.

Saran penulis terhadap objek penelitian bersifat operasional adalah dengan strategi pemasaran Lembaga Bimbingan Belajar Go Smart Banjarbaru dalam 7P yang dijalankan seharusnya dapat memaksimalkan 7P dan di analisis dengan SWOT guna meningkatnya dengan cara mengembangkan produk yang dimiliki Lembaga Bimbingan Belajar Go Smart Banjarbaru, rencana yang menyeluruh terpadu dan menyatu di bidang pemasaran yang memberikan panduan tentang kegiatan yang akan dijalankan Lembaga Bimbimbingan Belajar Go Smart Banjarbaru untuk mencapai tujuan perusahaan yaitu meningkatkan jumlah siswa.

\section{Kesimpulan}

Berdasarkan hasil analisis dan pembahasan yang disajikan pada bab sebelumnya untuk meningkatkan jumlah siswa melalui mega marketing 7P dan analisis SWOT pada Lembaga Bimbingan Belajar Go Smart Banjarbaru, maka dapat di simpulkan hal - hal sebagai berikut:

1. Dari keseluruhan produk yang disediakan oleh Go Smart terdapat salah satu keluhan dari konsumen yaitu progam bimbingan 1 tahun kelas regular, dikarenakan jumlah siswa perkelasnya 20 orang maka dari itu konsumen bearanggapan bahwa jumlah itu masih terlalu banyak sehingga menyebabkan siswa berhenti untuk les di Go Smart. Sedangkan untuk program - program yang lainnya masih berjalan dengan baik. Harga yang masih di anggap mahal bagi siswa pendaftar baru. Kegiatan promosi masih belum optimal karena tidak mempunyai wibesite. karena pada saat ini sangat berkembang teknologi yang diterapkan di Indonesia khusunya dan melihat keadaan tersebut banyak sekali masyarakat memanfaatkan media internet sebagai wahana pemasangan iklan atau sebagai media promosi dengan disertai profil detail dari lembaga tersebut serta tidak adanya Staf Marketing selama 3 tahun terakhir ini. Lokasi lembaga yang strategis dan mudah terjangkau dekat dengan sekolah sekolah favorit di Banjarbaru tetapi memiliki kelemahan karena dekat juga dengan lembaga pendidikan lain yaitu Ganesa Operasional, Prima Mandiri dan Primagama, Ketersediaan SDM atau tenaga pendidik di Lembaga Bimbingan Belajar Go Smart ini masih sangat dibutuhkan. Hal tersebut dikarenakan belum tersedianya tentor pengganti bagi tentor yang berhalangan mengajar dan belum tersedianya tentor khusus yang stanby untuk menangani kegiatan apabila sewaktu - waktu siswa tersebut mengalami kendala dalam hal belajar di luar jam belajar serta staf bagian marketing yang masih belum ada. Untuk Karyawan OB Go 
Smart masih tidak lancar dalam berbicara tentang program - program yang di sediakan oleh Go Smart Banjarbaru ketika memberikan penjelasan terhadap komsumen baru saat karyawan lain sedang jam istirahat. Kurangnya memperhatikan kebersihan toilat serta tempat parkir.

2. Dengan melakukan analisis SWOT Go Smart Banjarbaru harus melakukan kerjasama dengan sekolah saat pengambilan rapot, Melakukan sosialisasi ke siswa kelas ujung seperti kelas 6 SD, 9 SMP, 12 SMA dan menciptakan trik belajar menarik mengenai belajar pelajaran tersebut serta cara cepat untuk menjawab soal UN untuk menarik siswa dalam mengambil kelas tersebut, Selalu melakukan inovasi secara berkala untuk menjaga kulitas produk, Mengembangkan penyediaan tentor di Go Smart Banjarbaru sebagai pengganti tentor yang berhalangan dan membuat jam belajar yang sesuai dengan kebutuhan siswa.

Berdasarkan temuan dan kesimpulan di atas, terdapat beberapa saran yang perlu disampaikan terkait dengan strategi pemasaran lembaga bimbingan belajar Go Smart Banjarbaru sebagai berikut:

1. Bagi Lembaga Bimbingan Belajar Go Smart Banjarbaru perlu meningkatkan kualitas pemasaran dengan mengacu pada analisis SWOT dengan mengoptimalkan kekuatan dan peluang dengan mengembangkan program - program yang tersedia serta mampu meminimalkan kelemahan dan ancaman dari luar agar kegiatan pemasaran dapat berjalan sesuai dengan perencanaan.

2. Go Smart hendaknya melakukakan perekrutan tenaga kerja baru yang bertugas sebagai Staf Marketing.

3. Go Smart perlu menambah tenaga pengajar untuk dipekerjakan di Go Smart.

4. Go Smart perlu menyediakan tentor yang stanby .

5. Harus adanya pelatihan insentif bagi Ofiice Boy agar kinerja karyawan di Go Smart mempunyai keterampilan yang sama dan melakukan pelatihan terhadap tentor dari segi pelatihan metode pembelajaran, penambahan ilmu psikologi agar mampu memahami karakteristik para siswa.

6. Go Smart Banjarbaru perlu pembuatan website agar masyarakat dapat mengakses informasi mengenai program - programnya.

7. Serta harus menjaga kebersihan dengan sering melakukan pengecekan halaman depan dan toilet agar suasana di Go Smart terlihat bersih dan konsumen pun akan merasa nyaman.

8. Perlunya perbaikan kebijakan tentang konsultasi agar siswa tidak merasa terbatasi.

\section{DAFTAR PUSTAKA}

Abdullah, Thamrin dan Tantri,Francis, 2015, Manajemen Pemasaran, Raja Grafindo Persda, Depok.

Alma, Buchari, 2013, Manajemen Pemasaran dan Pemasaran Jasa, Alfabeta, Bandung.

Assauri, Sofjan, 2014, Manajemen Pemasaran, Raja Grafindo, Depok.

Fathonah, Kuni, 2016, Strategi Pemasaran Jasa Pendidikan Dalam Meningkatkan Pelayanan Pendidikan Di MAN 1 Sragen, http://eprints.iain-surakarta.ac.id/172/1/tesis\%20full.pdf (di akses 12/9/2017).

Fredy, Rangkuti, 2014. Business Plan, Gramedia, Pustaka Utama, Jakarta.

Gunarto, Bieli, Strategi Pemasaran, http://bieliegunarto.blogspot.co.id/2013/06/strategipemasaran.html. (01/09/2017).

Hanafiah, Vita, 2015, Strategi Pemasaran Lembaga Bimbingan Belajar Primagama Vila Nusa Indah Bogor, http://repository.uinjkt.ac.id/dspace/bitstream/123456789/28395/3/VITA\%HANAFIYA H\%20-\%20FITK.pdf (di akses 29/8/2017). 
Kolter, Keller, 2012, Manajemen Pemasaran, Penerbit: Erlangga, Jakarta.

Sutojo, F. Kleinsteuber, Kotler Analisis SWOT. http://www.psychologymania.com/2012/12/pengertian-analisis-swot.html (di akses $6 / 11 / 2017)$

Tjiptono, Fandy, 2014, Pemasaran Jasa, Andi, Yogyakarta.

Wardani, Kusuma, Rini, Aditya, 2016, Strategi Pemasaran Sekolah di SMPIP Baitul Maal Jurangmangu Kota Tanggerang Selatan, http://repository.uinjkt.ac.id/dspace/bitstream/123456789/33062/1/Aditia\%20Rini\%20K usuma\%20Wardani\%20-\%201110018200031\%20\%28watermark\%29.pdf (di akses 4/9/2017).

Yaqin, Ainul, Ahmad, 2016, Strategi Pemasran Pendidikan di Madrasah aliyah Unggulan Pondok Pesantren Amanatul Ummah Surabaya, http://jurnalmahasiswa.unesa.ac.id/article/19891/16/article.pdf (di akses 5/10/2017).

Zannah, Fitriatul, 2017, Manajemen Pemasaran Modern dan Service Marketing, Makalah Seminar Strategi Pemasaran unutk meningkatkan Penjualan Pada Toko Xander Modification, Kota Banjarbaru.

Zagladi, Arief Noviarakhman, Fredy Jayen dan Sutrisno 2017, Pedoman Penulisan Skripsi STIE Pancasetia Banjarmasin, Pancasetia, Banjarmasin. 